\title{
Phytin: A Nutritional Inhibitor in Food and Feed - Review of Strategies and Challenges to Overcome the Menace in Maize
}

\author{
Vimla Singh ${ }^{1}$, Rakesh Mehra ${ }^{2 *}$, Sunaina Bisht ${ }^{3}$, Meena Shekhar ${ }^{1}$, and Arvind Kumar ${ }^{1}$ \\ ${ }^{1}$ ICAR-Indian Institute of Maize Research, Pusa campus, New Delhi (Delhi) - 110012, India \\ ${ }^{2}$ C.C.S. Haryana Agricultural University, Regional Research Station, Karnal (Haryana) - \\ 1320001 (India) \\ ${ }^{3}$ Division of Plant Pathology, Indian Agricultural Research Institute, Pusa Campus, New \\ Delhi (Delhi) - 110012, India
}

*Corresponding author

\section{A B S T R A C T}

Phytin, or myo-inositol hexakisphosphate (InsP6), is stored form of phosphorus (P) seeds of cereals and legumes. It has a strong tendency to chelate metallic cations $\mathrm{Ca}, \mathrm{Fe}, \mathrm{K}, \mathrm{Mg}$, $\mathrm{Mn}$ and $\mathrm{Zn}$ and form insoluble complexes which renders them unavailable to animals or humans fed on seed diet. The undigested $\mathrm{P}$ is released in excreta and spreads as manure

\section{Keywords}

Phytin, Approaches for dephytinization; Low phytin maize

Article Info

Accepted: 22 May 2018 Available Online: 10 June 2018 into the soil causing eutrophication of water bodies also due to run off. In maize (Zea mays) $90 \%$ of the phytin occurs in the germ portion of the kernel, while in wheat and rice it is stored in aleurone layers of the kernel and the outer bran and acts as anti nutritional factor. Apart from reducing the dietary nutritional value, phytin plays several positive roles in metabolism, viz., protein and carbohydrate metabolism, responding to oxidative stress, draught tolerance by inducing stomatal closure, prevents senescence and apoptosis, regulates phosphate homeostasis and acts as shelter factor for maturing embryo in the seeds. Application of phytin is also reported in paper preservation, meat preservation, body metabolism and also cancer therapy. Phytin also has probable role in disease resistance in plants; however, much information is not available. Inspite of so many positive roles for plants, the economic value of feed and food is greatly reduced due to the anti nutritional attribute of the seed phytin. In this review we discuss the approaches and challenges to overcome the menace of phytin in food and feed to improve bioavailability of minerals and maintaining seed phytin to desired levels for normal plant metabolism.

\section{Introduction}

Maize (Zea mays L.) seeds forms an important ingredient of feed for poultry and swine and also a food for humans. In seeds stored phosphorus (P) largely occurs as phytin or Phytic acid (PA) a myo-inositol hexakisphosphate, Ins $(1,2,3,4,5,6) \quad P 6$, or InsP6. PA content is a major concern for nutritive value of maize. It is the storage compound of phosphorus in seeds accounting for up to $80 \%$ of the total seed phosphorus and contributing as much as $1.5 \%$ to the seed dry weight. The negatively charged phosphate in 
PA strongly binds to metallic cations of $\mathrm{Ca}$, $\mathrm{Fe}, \mathrm{K}, \mathrm{Mg}, \mathrm{Mn}$ and $\mathrm{Zn}$ making them insoluble and thus unavailable as nutritional factors (Bohn et al., 2008). Also, PA reduces the phosphorous availability required for growth in monogastric animals, which digest PA poorly. Moreover, undigested PA eliminated by the monogastric animals into the environment leads to an increase in phosphorous level in the environment and contributes to water pollution through eutrophication (Cromwell and Coffey 1991). When released during food or feed processing or in the gut, PA binds minerals and makes them unavailable and hence PA is an antinutritional factor, which causes malnutrition in human (Zhou and Erdman 1995). Hence, phytin-P is poorly available to poultry and swine. Enzyme phytase releases phosphate groups from phytin and $\mathrm{P}$ is available to the animal, thereby reducing $\mathrm{P}$ excreted from poultry and swine. Phytase is the only recognized enzyme that can facilitate the release of phosphate from phytin (IUB, 1979).

Phytic acid plays several positive roles in plant metabolism hence it is not beneficial to completely eliminate it from food. Phytic acid concentrations in seeds depend upon cultivars, soil conditions, fertilizer applications, available moisture content and other climate factors (Nelson et. al., 1968). Lott et al., (2000) have reported that the range for phytic acid in cereal grains is $0.86-1.06 \%$, while Reddy et al., (2002) have obtained values between 0.50 and $1.89 \%$. PA is also an important mineral reserve in seeds, and it is stored in protein storage vacuoles in the aleurone cell layer or the embryo of the seed.

Feed supplemented with inorganic phosphate or with industrially produced phytase enzyme, which breaks down PA and releases phosphorous for animal use, can address the phosphorous requirement for animal growth and reduce phosphorous pollution. However, phosphate and phytase supplementation increase the animal feed costs. In maize (Zea mays) $90 \%$ of the phytin is stored in the germ portion of the kernel, while in wheat and rice aleurone layers of the kernel and the outer bran are the primary storage sites (O'Dell et al., 1976). The means that within relatively closely related grasses different control points exist for PA biosynthesis and assimilation exist. PA biosynthesis initiates after flowering and it accumulates during development up to seed maturation and desiccation.

In this review we discusses the physical and chemical properties of Phytin, it role in plant metabolism and the approaches to overcome this menace to improve the nutritional value of food and feed. This review presents a compilation of all available approaches to improve the nutritional value of food and feed with maize as ingredient.

\section{Phytin: Healthy or harmful?}

Phytic acid originates in plant seeds from natural mineral sources in soil or from fertilizers (Fig. 1)

Phytin-P content in feedstuffs varies from 72 and $60 \%$ of total seed $\mathrm{P}$ in corn and soybean meal (SBM), respectively, which form the poultry and swine diets. Phytic acid chelates with $\mathrm{Ca}, \mathrm{Fe}, \mathrm{Mg}, \mathrm{Cu}, \mathrm{Zn}$, carbohydrates, and proteins and forms less soluble complexes in the small intestine which are not hydrolyzed to release phosphorus for nutrition. Hence, phytin acts as an anti-nutrient factor. The unutilized $\mathrm{P}$ is excreted by the animal. Phytin in feedstuffs is relatively thermostable (O'Dell 1962). The phytate phosphorus is calculated from the ferric ion concentration assuming a 4:6 iron: phosphorus molar ratio:

$$
\text { The phytate }=\frac{6}{4} \times \frac{\text { A } \times \text { mean } k \times 20 \times 10 \times 50 \times 100}{1000 \times 2} \mathrm{mg} / 100 \mathrm{~g} \text { sample, }
$$

Where, $A$ is optical density. 
Phytin $\left(\mathrm{C}_{6} \mathrm{H}_{18} \mathrm{O}_{24} \mathrm{P}_{6}\right)$ is chemically myoinositol $(1,2,3,4,5,6)$ hexa-kisphosphate, structurally consisting of hydroxylated inositol ring and at least one phosphate group sterically stable at $\mathrm{pH}$ range $0.5 \sim 10.5$. Agranoff (1978) described the structure as a turtle's limb. The four limbs and tail of the turtle are coplanar and represent the five equatorial hydroxyl groups (Fig.2).

The order of forming complexes with mineral cations in vitro with inositol phosphates is found to be $\mathrm{Cu}^{2+}>\mathrm{Zn}^{2+}>\mathrm{Cd}^{2+}$ for all InsP3 InsP6 at pH 3 7, but binding strength is weaker for the lower inositol phosphates (Persson et al., 1998). Vohra et al., (1965) also reported the order $\mathrm{Cu}^{2+}>\mathrm{Zn}^{2+}>\mathrm{Ni}^{2+}>\mathrm{Co}^{2+}>\mathrm{Mn}^{2+}>\mathrm{Fe}^{3+}>\mathrm{Ca}^{2+}(\mathrm{Boh}$ n et al., 2007, 2008; Raboy, 2003). Thus, iron uptake is inhibited by strong chelators such as PA and some polyphenols having a chatechol group in their structure which form very stable chelates (Tuntawiroon et al., 1991).

Studies on germinability, free iron level, free radical relative abundance, protein carbonylation level, damage to DNA, degree of lipid peroxidation, $\alpha$ - and $\beta$-tocopherol amount and antioxidant capacity of maize seeds from low phytic acid mutant revealed that, phytin provides protection against oxidative stress and antioxidant action (Berjak and Pammenter, 2003). Phytic acid is signal transducer for appropriate response to oxidative stress, and detoxifies reactive oxygen species during seed maturation thus, protects the embryo. It is directly involved in signal transduction events in guard cells (Lemtiri-Chlieh et al., 2003), plays a role in the abscisic acid (ABA) induced stomatal closure, conserving water and ensuring plant survival. Over increase in free phosphate level may perturb phosphorus homeostasis during seed maturation and interferes with phosphorylation cascade involved (Pilu et al., 2003). In the aerobic cell environment, if iron cations are not chelated or sequestered by other molecules it can give rise to reactive oxygen species which may damage cell molecules and structures causing cell senescence and apoptosis phenomena. Therefore, phytic acid maintains the phosphate homeostasis in maturing seed and acts as a 'shelter factor'.

The chelating ability of PA is also used in preserving paper, having ink made from gallic acid derived from the tannins. Phytic acid prevents iron catalysed oxidation of the cellulose in the paper, thus enhances the halflife of the documents (Neevel, 1995). InsP5s inhibits free radical formation (Hawkins et al., 1993), which also preserves paper (Sala et al., 2006). The PA mediated inhibition of $\mathrm{Fe}$ dependent reactions is also used for storage of meat (Stodolak et al., 2007). In mammals, PA has helps in starch digestion and blood glucose response (Lee et al., 2006), prevents dystrophic calcifications in soft tissues (Grases et al., 2006) and kidney stone formation (Selvam, 2002), lowers cholesterol and triglycerides (Onomi et al., 2004). PA is reported to inhibit transcription of the viral genome from HIV-1 (Filikov and James, 1998), and tested in toothpaste for preventing plaque formation (Vasca et al., 2002). At the cellular level, PA is involved in gene regulation, efficient export of mRNA, RNAediting and DNA repair (York, 2006). The lower inositol phosphates take part in cell signaling cascades (Berridge and Irvine, 1989) and pathways involved in $\mathrm{Ca}^{2+}$ mobilisation and signalling (Efanov et al., 1997; Larsson et al., 1997). It also helps in protein folding (Macbeth et al., 2005) and trafficking (Shears, 2004), endo- and exocytosis (Efanov et al., 1997; Saiardi et al., 2002), oocyte maturation (Angel et al., 2002), and cell division and differentiation (Berridge and Irvine, 1989).

Phytic acid has role in cancer therapy also (Vucenik and Shamsuddin, 2006). The lower 
inositol phosphates act as an antioxidant by inhibiting iron mediated oxidative reactions, enhancing immunity by its 'Natural Killer cell function' activity. Also, they normalise abnormal cell proliferation, induce cell differentiation and apoptosis inhibiting angiogenesis. The inositol phosphates modify Phases I and II metabolising enzymes by causing $\mathrm{G}_{0} / \mathrm{G}_{1}$ arrest in cancer cells, thus, modulating oncogene expression, and prevent tumor metastasis formation. Mammalian cells can synthesize the inositol phosphates themselves (York, 2006), however, endogenous synthesis of phytic acid is minor. Hence, cancer therapy using phytic acid would require daily intake of phytic acid and will be influenced by the absorption rate of PA (Grases et al., 2006).

Regarding the negative functions of phytic acid, a high PA diet causes mineral deficiency and malnutrition. The chelating ability of phytic acid renders it to be an anti nutritional factor. The phytic acid: metal-complexes are weakly soluble in major part of the intestines (Sandberg et al., 1999). Phosphorous in the form of phytic acid is largely unavailable as a nutritional factor to the monogastric animals. Animal feeds therefore supplemented with inorganic phosphate to meet the nutritional requirements for optimal growth of the animals. The excess of phosphorous in phytic acid is excreted through the faeces and spreads as manure into the soil. This leads to eutrophication of fresh water streams, lakes and near coastal areas causing cyanobacterial blooms, hypoxia, death of aquatic animals and production of nitrous oxide, a greenhouse gas (Vats et al., 2005). In the laboratory tests, phytic acid in faeces also inhibits polymerase chain reactions (PCR), thereby preventing PCR-based diagnostic. Murphy et. al. (2008) reported probable role of phytic acid in resistance against TMV, turnip mosaic virus, cucumber mosaic virus and cauliflower mosaic virus as well as to the fungus Botrytis cinerea and to $P$. syringae suggesting that a specific pool of InsP6 involed in salicylic acid pathway regulates defense against phytopathogens.

\section{Approaches for lowering Phytin in food and feed}

\section{(a) Dephosphorylation by Phytases}

The enzyme phytase is a novel and cost effective tool in poultry and swine for improving $\mathrm{P}$ utilization from phytin diets. Phytases are phosphatases (myo-inositol $(1,2,3,4,5,6) \quad$ hexakisphosphate phosphohydrolase) which can release phosphate from PA. Microbial phytases discovered from Aspergillus ficuum (Ullah and Phillippy, 1988) are in use now-a-days. Monogastric animals, including humans, lack phytases for hydrolysis of PA in their digestive tract (Lei and Porres, 2003). Phytases potentially improve mineral bioavailability in food applications due to their higher thermostability favouring efficient degradation of phytic acid. For a 'phytatefree' after ingestion several factors are considered: form of the diet (pelleted, mash, or liquid), phytate concentration, microbial source, solubility, protein concentration and type, phytase type, location of addition of phytase (post-pelleting or mixer), dose, vitamin $\mathrm{D}$ status of the animal, water characteristics, dietary calcium concentration and the need exogenous enzymes supplement (coated, size of the particle, etc.), temperature, and $\mathrm{pH}$ optima of the enzyme, diet mineral concentration $(\mathrm{Ca}, \mathrm{Fe}, \mathrm{Mg}, \mathrm{Cu}$, and $\mathrm{Zn})$, ingredients used in the diet, diet manufacturing methodology, disease status of the animal, and other factors (Cowieson et. al., 2014). Feedstuffs made of corn, oats, sorghum, and oilseeds have little or no phytase activity (Eeckhout, and de Paepe, 1994). Adding fungal phytase in diets for poultry reduces $\mathrm{P}$ excretion by the animal. Kornegay, 
(1999) reported that, $1000 \mathrm{U} / \mathrm{kg}$ of fungal phytase included in corn/SBM-based diets of pigs, increased $\mathrm{P}$ retention from 52 to $64 \%$ and $50 \%-60 \%$ in boilers. Commercial phytases are produced using recombinant DNA technology for improved functional use of phytases better thermostability, $\mathrm{pH}$ specificity, and resistance to break-down by other digestive enzymes in the animal.

Removal amounts of $\mathrm{P}$ for 500 units of phytase / $\mathrm{kg}$ diet varies from $0.06 \%$ to $0.10 \%$ for broilers, turkeys, and swine (500-1000 $\mathrm{U} / \mathrm{kg}$ ). Phytases are used in the nursery with 250 to $1000 \mathrm{U}$ used in grow/finish and sow diets), 300 units of phytase / $\mathrm{kg}$ diet for laying hen. In swine, typically higher levels are required. The E. coli- based phytases are more efficient in the animal than the Aspergillus and Peniophora derived phytases (Applegate et al., 2003). There is limited data available regarding the efficacy of the different phytases at concentrations above those suggested by the manufacturer. Hence, it is difficult to give an accurate estimate of $\mathrm{P}$ released when phytases are used beyond their recommended levels. Plant phytases work better at 45 to $60^{\circ} \mathrm{C}\left(113\right.$ to $\left.140^{\circ} \mathrm{F}\right)$ whereas microbial phytases work on a wider temperature range $\left(35\right.$ to $63^{\circ} \mathrm{C} ; 95$ to $145^{\circ} \mathrm{F}$ ) (Wodzinski and Ullah, 1996). One unit of phytase is defined as the amount of enzyme required to liberate $1 \mu \mathrm{mol}$ of orthophosphate from phytin per minute at $\mathrm{pH} 5.5$ and $37^{\circ} \mathrm{C}$ (Zyla et al., 2013).

The maize roots phytases are isoformas of D/L- 6-phytases and are completely different from the 3-phytase or 5-phytase from Aspergillus ficuum (Ullah and Phillippy, 1988). Currently, 3 classes of phytase enzymes are characterized (IUB 1979) which initiate the dephosphorylation of PA at different positions on the inositol ring, and produce isomers of the lower inositol phosphates. EC 3.1.3.8: the 3-phytases, is the largest group found in fungi and bacteria, structurally homologous to $\beta$-propeller phosphatase (BPP), or histidine acid phosphatases (HAP). BPPs chelate three $\mathrm{Ca}$ ions. Most microbial and plant phytases belong to the HAPs which initiate hydrolysis of phytic acid on either the C3 or the C6 position of the inositol ring (Greiner and Carlsson, 2006). EC 3.1.3.72: the 5-phytase is the only known 5-phytase (EC 3.1.3.72) so far isolated from lily pollen with highest activity at $\mathrm{pH} 8.0$ and temperature $55{ }^{\circ} \mathrm{C}(\mathrm{Jog}$ et al., 2005). EC 3.1.3.26: the 4/6-phytases are 4/6phytases (EC 3.1.3.26) also called a 6-phytase, include plant phytases. They are most active in weakly acidic environments ( $\mathrm{pH} 4 \sim 6$ ) with a temperature optimum in the range $40 \sim 60{ }^{\circ} \mathrm{C}$.

The first commercially available phytase was isolated from Aspergillus niger (NatuphosTM, BASF) in 1991, but now several phytases are commercially available, from e.g., Peniophora lycii (RonozymeTM, DSM/Novozymes), Escherichia coli (QuantumTM, Diversa/Syngenta) and Schizo saccharomyces pombe (PhyzymeTM, Diversa/ Danisco). However, a cost-effective and efficient production strategy is lacking for production of plant phytases.

\section{(b) Production of phytase in transgenic plants}

For in planta production of phytases in the feed, thermostability of the enzyme is a constraint (Brinch-Pedersen et al., 2006). "Biofarming" of the phytase can be a costeffective approach to its production. Commonly, cauliflower mosaic virus (CaMV) $35 \mathrm{~S}$ promoter is used for the construct which gives enzymes with almost similar characteristics as the fungal phytase, except minor changes in $\mathrm{pH}$ optima and sizes. Heat stable $A$. fumigates phytase expressed in tobacco leaves and Pichia pastoris also has great potential (Wang et al., 2007). Bacillus 
mucilaginosus, in soil expresses high phytase activity extracellularly and degrades PA in the soil, thereby potentially limiting eutrophication (Li et al., 2007).

\section{(c) Phytase as feed additive}

Exogenous phytases in feed increase mineral, phosphorous and energy uptake and decreases phosphorous excretion thereby, reduces eutrophication in water supplies. Supplements of microbial phytase increased $\mathrm{P}$ availability by $38 \%, 12 \%$ and $15 \%$ in pig diets containing maize, wheat and triticale, respectively (Dungelhoef et al., 1994), and up to $60 \%$ reduction in manure $\mathrm{P}$ (Nahm, 2002). In broiler chickens also, exogenous phytase supplement reduces the excretion of endogenous amino acids, calcium, sodium, phytate phosphorus and sialic acid significantly (Cowieson et al., 2004; Nahm, 2002)

\section{(d) Phytase as food additive}

Phytase potentially of decreases phytate content, releasing calcium thereby, promotes the activation of endogenous $\alpha$-amylase. Iron absorption from porridges from rice, wheat, maize, oat, sorghum and wheat-soy flour is improved by cereal porridges prepared with water but not with milk, with addition of ascorbic acid (Haros et al., 2001).

\section{(e) Transgenic livestock}

Creating transgenic livestock is another approach. A transgenic pig that constitutively secretes microbial phytase from the salivary glands shows up to $75 \%$ reduction in phosphorous excretion. Also, its requirements for inorganic phosphorous supplements are almost zero. Similarly, another group has experimented with expressing an avian phytase in chickens (Ward, 2001; Cho et al., 2006).

Fig.1 Schematic representation of absorption of phosphate from soil and biosynthesis of phytate

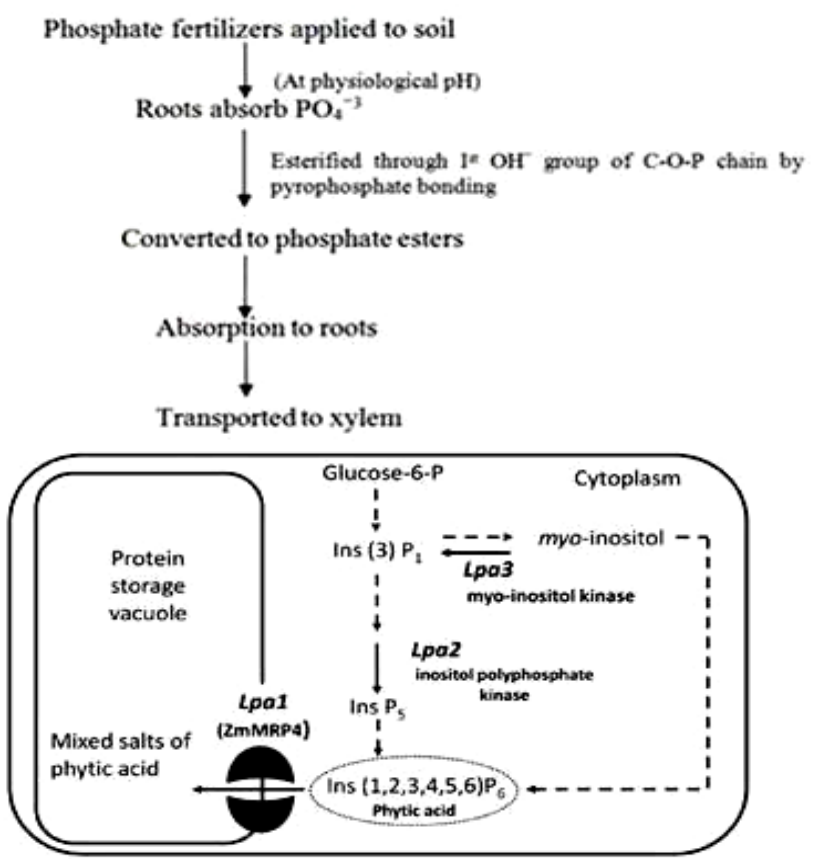


Fig.2 Structure of phytic acid with different possibilities to chelate with cations (Source: Coulibaly et. al. 2011, Am. J. Plant Nutr. Fert. Technol.)

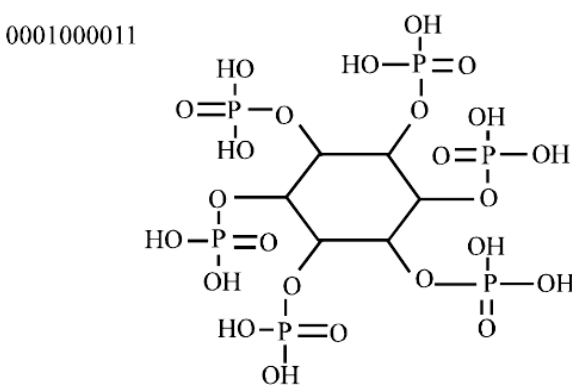

\section{(f) Low-phytic acid (lpa) genetics and breeding}

Low-phytic acid (lpa) mutations were first isolated in the cereal grains maize (Zea mays), barley (Hordeum vulgare) and rice (Oryza sativa). More than 20 independent lpa mutations have been isolated in both maize and barley, showing reduction in seed phytic acid $\mathrm{P}$ ranging from $50 \%$ to $95 \%$. The high inorganic P (HIP) phenotype of lpa seeds provides the basis for a quick, sensitive and inexpensive test for the trait, for plant breeding purposes. Using HIP phenotyping, the first maize lpa mutation, lpal-1 has been introduced into a number of maize inbred lines, by traditional backcrossing breeding methods. Currently, the most work and progress concerning low-phytate crops has been accomplished with this first maize mutant, with 55-66\% lower phytic acid content compared with normal seeds (Chen. et. al. 2008).

Several pairs of near-isogenic lines have been developed for maize inbreds for use as parents to produce pairs of near-isogenic maize hybrids. These sets of near-isogenic inbreds and hybrids are a powerful experimental model to study the effects of lpa mutations on plant, seed growth and function, agronomic performance, as well as human nutrition and health. Studies reveal no effect on

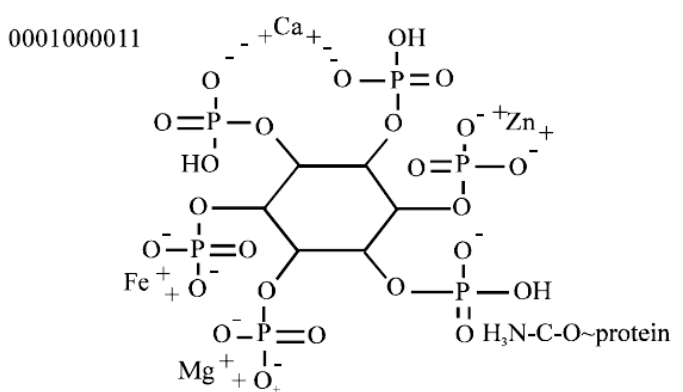

germination in the field or in a cold-test, stand establishment, lodging, plant height, ear height, and growth rate in the field and grain moisture. However, low yield compared with the normal hybrid, is recorded. This opens classical genetics approach to produce hybrids or cultivars with seeds having reduced $(\sim 50 \%)$ phytic acid and good productivity for a first-generation technology. But, more data is needed on the impact of these mutations on stress response or disease susceptibility. The biotechnology approach can be successful for characterizing target manipulating target gene expression only in specific tissues of the developing seed, avoiding any undesirable effects on plant growth and productivity.

\section{(g) Transgenic approaches}

To overcome the menace of phytate, phytasetransgenic (PT) maize has been developed by achieving seed-specific over-expression of Aspergillus niger phytase (phyA2), an enzyme catalyzing the release of phosphate from phytate (Chen. et. al. 2008). Tan et. al., (2017), studied comparative proteomics of the seeds of phytase transgenic (PT) and nontransgenic (NT) maize using 2-DE and iTRAQ techniques and identified 148 differentially expressed proteins (DEPs) (42 up-regulated and 106 down-regulated) in PT maize seeds compared with NT maize seeds. Most of the DEPs were involved in posttranscriptional regulation and modification 
functions in PT maize seeds. Many studies were performed to ensure the safety of PT maize, viz., nutritional value (Gao et. al., 2012), used as livestock feed (Li et. al., 2013), and effect on associated arthropod communities in the field (Tan et. al., 2016).

$\begin{array}{llc}\text { Omics-based } & \text { studies, } & \text { including } \\ \text { transcriptomics } & \text { (mRNA } & \text { profiling), }\end{array}$ proteomics (protein profiling) and metabolomics (metabolite profiling), conducted in maize by Gong and Wang, (2013) revealed a comparison of the proteomic profiles of GMCs and corresponding wild-type lines. Detailed information on DEPs (differentially expressed proteins) involved in metabolism and cellular development or those involved as toxins, antinutrients and allergens could be generated. Protein profiles revealed significant differences between GMCs and their control lines (Albo et al., 2007; Zolla et al., 2008; Balsamo et al., 2011; Vidal et al., 2015). BVLA430101 transgenic maize line, which over-expresses an Aspergillus niger phytase (phyA2) has been approved as a potential biosafety species by the Chinese Academy of Agricultural Sciences (Chen et al., 2008). This phytase GM line expresses the $60 \mathrm{kDa}$ phyA 2 protein in its seeds, showing a higher phytase activity than non- transgenic maize seeds (Chen et al., 2008). Kuiper et al., (2001) studied potential unintended effects of 57 identified proteins by global profiling technique and reported that $40 \%$ proteins were related to carbohydrate transport and metabolism, $12 \%$ related to post-translational modification and $11 \%$ regulated to coenzyme metabolism. Several proteins regulated other pathways, including energy production and conversion, inorganic ion transport and metabolism, translation, ribosomal structure and biogenesis, the cytoskeleton, amino acid transport and metabolism, cell cycle control, cell division, chromosome partitioning, signal transduction, and lipid transport metabolism.
The differences were not homogeneous hence; unintended effects are not unique to GM plants (Ladics et al., 2015).

(h) Breeding, germplasm screening and biotechnological approache

Low phytin-P corn genotypes (LPA) have been developed to overcome the menace of phytin. In LPA corn only $35 \%$ of the total $\mathrm{P}$ is phytate-P compared to $75-80 \%$ in normal corn. The P in LPA corn and soybean meal is more available (Cromwell et al., 2000a, b; Spencer et al., 2000) and can reduces litter $\mathrm{P}$ from broilers by $58 \%$ (Applegate et al., $2003 \mathrm{~b}$ ) and $\mathrm{P}$ excretion from pigs by $37 \%$ (Spencer et al., 2000b). De-hulled and degermed corn (DDC) is a produced by dry milling industry with Phytin-P deposited in protein bodies of the aleurone $(10 \%)$ and scutellum (90\%) of corn grain (O'Dell et al., 1972). Removal of the germ layer during drymilling, removes a large amount of phytin-P located in the scutellum. In diets formulated with DDC corn grain has $20 \%$ less $\mathrm{P}$ being excreted by broilers and 30 to $35 \%$ less in swine. However, there is risk of stomach ulcers in swine.

Vitamin $\mathrm{D}_{3}$ metabolites can also reduce $\mathrm{P}$ excretion by stimulating $\mathrm{P}$ transport mechanisms in the intestine which enhances the activity of supplemented phytase. Breeding for low phytate maize genotypes can be effectively used for reducing the content of kernel phytic acid (which chelates mineral cations such as $\mathrm{K}, \mathrm{Ca}, \mathrm{Fe}, \mathrm{Mg}$ and $\mathrm{Zn}$ ) and improving bioavailability of nutrients in human and animal diet as well as decreasing the environmental pollution by $\mathrm{P}$ released from undigested and unutilized phytic acid (Ertl et al., 1998; Mendoza et al., 1998).

Many low phytic acid mutants have been developed by disrupting phytic acid 
biosynthesis through mutation breeding in maize, rice, barley, and soybean (Raboy et al., 2000) for use in genetic breeding for low phytate lines. So far, in maize, three low phytic acid (lpa) mutants have been isolated, viz. lpa1, lpa2 and lpa3 which are valuable genetic resources to develop low phytin maize crops. The lpal mutant is derived from mutation in gene that encodes transmembrane transporter protein (ZmMRP4), which loads phytic acid into protein storage vacuoles of maize seed. The lpa2 mutant is obtained by a mutation in inosotol phosphate kinase gene (ZmIpk4), which along with other kinases leads to phytic acid synthesis. Compared with wild-type kernels, the lpa 1, lpa2, lpa3 mutations achieved 66\%, 50\% and $50 \%$ reduction in phytic acid content, respectively (Raboy et al., 2000; Shi et al., 2005). The mutant lines perform well in temperate and not adapted to local tropical and subtropical conditions. Therefore, there is a need to have the lpa locus introgressed into locally adapted agronomically superior lines to improve their nutritional benefit. Marker assisted backcross breeding (MABB) is an effective strategy for developing low phytate maize which may provide success for transfer of desirable trait of interest into recipient by recurrent backcrossing and recovery of the recurrent parent genome efficiently. Thus, the development of a co-dominant molecular marker can enable quick selection for LPA maize breeding for faster release of lpa varieties. Reducing phytate content through lpa mutants have been attempted through knock-out of genes involved in PA biosynthesis. The mineral composition does not change in lpa mutants, indicating that there is no direct link between mineral distribution and phytic acid biosynthesis (Liu et al., 2004; 2007). However, this can be a reasonable approach to enhancing the bioavailability of micronutrients.

Due to the involvement of the lower inositol phosphates in plant cell metabolism, developing a perfect lpa mutant has is a challenge as, many kinases and tranferases are involved in the synthesis of phytic acid (Josefsen et al., 2007). Furthermore, the yield or germination ability is affected if PA content is reduced more than 50\% (Raboy, 2002), thereby making this approach less economic. The best result so far is the maize lpal mutant, which is mutated in an embryospecific ATP binding cassette (ABC)transporter and it is able to hold up to $90 \%$ reduction of $\mathrm{PA}$ without compromising seed viability. The effect on mineral distribution in this mutant is not evaluated yet (Shi et al., 2007). Maize, millet and sorghum have low initial phytase activity that increase rapidly after germination (Egli et al., 2002). Estimation of inorganic phosphorous by 'high inorganic phosphorous' (HIP) assay can help to indirectly estimate the phytic acid content of maize kernels. However, lpa2-2 allele specific marker is lacking for selecting plants with lpa2-2 alleles. Therefore, SSR marker, that is tightly associated and hence cosegregating with lpa2-2 allele needs to be developed.

\section{(i) Biofortification (Genetic modification in maize)}

Anemia due to iron deficiency afflicts an estimated 2 billion people worldwide, particularly in developing countries such as Asia and Africa, whose populations are sustained on a few staple food crops. Biofortification programs based on conventional breeding consider existing genotypic differences in seed $\mathrm{Fe}$ concentrations to identify cultivars with improved Fe content. Considerable progress has been made in recent years to modify seed iron content via genetic engineering by overexpressing different Fe-regulated proteins in target food crops. Ferritin has been widely used to enhance $\mathrm{Fe}$ content of staple food crops, due to its high-Fe binding capacity ( 4,500 atoms of Fe/molecule). These 
biotechnological efforts show only marginal success. Lpal-1 mutant of maize has been developed as a tool for iron biofortification to combat anemia with iron biofortification of staple food crops. Studies reveal that there was no significant correlation between $\mathrm{Fe}$ content and bioavailability. Furthermore, the transgenic approaches in maize led to a little improvement in $\mathrm{Fe}$ content $(\sim 30-35 \mu \mathrm{g} / \mathrm{g})$. Variation in transgenic maize is a common phenomenon due to issues like germplasm used for transformation, transgene copy number, or changes in the expression of genes (epigenetic effects). The lpa mutants have poor seed quality and crop yield. Thus, a better understanding of plant iron homeostasis and the probable limiting factors is required. Studies revealing the significance of phytasemediated improvements in iron absorption and iron status is still low along with a more detailed understanding of uptake mechanism for iron released from partially dephosphorylated phytate chelates, the affinity of microbially derived phytases towards insoluble iron phytate complexes, and the extent of phytate dephosphorylation required for iron release from inositol phosphates is required.

\section{(j) Other conventional method}

Phytic acid prevents the absorption of phosphorus as well as $\mathrm{Fe}, \mathrm{Mg}, \mathrm{Ca}, \mathrm{Zn}$ and negatively affects absorption of lipids and inhibits enzymes viz., pepsin, amylases and trypsin. To reduce phytic acid menace following conventional techniques are followed

\section{Germination and sprouting}

Soaked seeds imbibe moisture which allows mobilization of primary and secondary metabolites favouring germination. Surface sterilization with $0.1 \%$ lemon extract can avoid mould contamination. Phytic acid reduction $\sim 28 \%$ to $60 \%$ can be achieved However, in maize seeds the reduction is quite low (Poiana et. al., 2009).

\section{Fermentation}

Fermentation provides optimum $\mathrm{pH}$ for hydrolysis of phytic acid and release of polyvalent cations $\mathrm{Fe}, \mathrm{Zn}, \mathrm{Ca}, \mathrm{Mg}$, proteins in soluble form. Reale et. al., 2004 studied effects of Lactobacillus Plantarum, L. brevis, L. curvatus and Saccharomyces cerevisiae strains on $\mathrm{IP}_{6}$ hydrolysis by Italian Sourdough technique and reported a positive correlation between lactic acid and endogenous phytase activity at optimum $\mathrm{pH} 5.5$.

\section{Enhancing Iron Absorption}

Pretreatment of grains by soaking, malting, germination and addition of organic acids, viz., ascorbic acid and citric acid, enhances iron absorption. Such classical pretreatments serve to activate the endogenous cereal phytases.

In conclusion, high phytate content in staple food crops is a major barrier to successful iron biofortification. Low phytic acid (lpa1-1) mutant of maize has been exploited to generate transgenic plants with up-to $70 \mu \mathrm{g} / \mathrm{g}$ seed iron through the endosperm specific overexpression of soybean ferritin, with enhanced iron bioavailability. To combat the menace of phytin in diet approaches for genetically modified crops, with low phytate content / higher phytase activity, have revealed little success. Direct fortification of foods and iron supplementation are still potential solutions to improve the iron status of vulnerable populations. However, iron supplementation works in combination with phytase-mediated degradation of phytate. Options for improving phytase stability in the gut need to be investigated, including genetic engineering and/or formulation approaches. 
To improve our understanding the research emphasis should be on estimating inositol phosphate contents as well as phytate: iron ratios in the final digested/pretreated food. These parameters crucially determine iron absorption in vivo. Further, research on the exact chemical form of iron and phytate in the stomach and cellular uptake from loosely chelated iron to lower inositol phosphates needs to be elucidated to study the mechanism of phytase-mediated iron release and absorption in the human body. A deeper understanding of the significance of phytase dosage, kinetics (i.e., rates of dephosphorylation), and stability under gastrointestinal conditions may help in identifying the intelligent solutions for in vivo phytase catalysis and defining the efficacy of phytase-mediated iron release. With more emphasis on these issues, engineering of better dietary solutions for improved iron absorption from cereal and other plant foods can be possible.

\section{References}

Agranoff, B.W., (1978). Textbook errorsCyclitol confusion. Trends in Biochemical Sciences, 3(12): N 283-N 285

Albo, A. G. et al., (2007). Proteomic analysis of a genetically modified maize flour carrying Cry1 $\mathrm{Ab}$ gene and comparison to the corresponding wild-type. Maydica. 52, 443-455.

Angel, R., N.M. Tamim, T.J. Applegate, A.S. Dhandu, and L.E. Ellestad, (2002). Phytic acid chemistry: influence on phytin -phosphorus availability and phytase efficacy. J. Appl. Poult. Res. 11:471-480.

Applegate, T.J., D.M. Webel, and X.G. Lei. (2003). Efficacy of E. coli Phytase expressed in yeast on phosphorus utilization and bone mineralization in turkey poults. Poult. Sci. 82:1726-1732.
Balsamo, G. M., Cangahuala-Inocente, G. C., Bertoldo, J. B., Terenzi, H. \& Arisi, A. C. (2011). Proteomic analysis of four Brazilian MON810 maize varieties and their four non-genetically-modified isogenic varieties. J Agric Food Chem. 59, 11553-11559, doi:10.1021/ jf202635r.

Berjak P, Pammenter N. (2003). Orthodox and recalcitrant seeds. In: Vozzo J, ed. Tropical tree seed manual. United States Department of Agriculture, Forest Service, 137-147.

Bohn, L., Meyer, A. S. and Rasmussen, S. K. (2008). Phytate: impact on environment and human nutrition. A challenge for molecular breeding. - J. Zhejiang Univ. Sci. B 9: 165 - 191.

Brinch-Pedersen, H., Hatzack, F., Stoger, E., Arcalis, E., Pontopidan, K., Holm, P.B., (2006). Heat-stable phytases in transgenic wheat (Triticum aestivum L.): Deposition pattern, thermostability, and phytate hydrolysis. Journal of Agricultural and Food Chemistry, 54(13):4624-4632. [doi:10.1021/jf0600152]

Brune, M., Rossander, L., Hallberg, L., (1989). Iron-absorption and phenolic compounds-Importance of different phenolic structures. European Journal of Clinical Nutrition, 43(8):547-558.

Chen, R. et al., (2013). Corn seeds as bioreactors for the production of phytase in the feed industry. $J$. Biotechnol. 165, 120-126.

Chen, X.; Lin, W.; Wang, Y.; Luan, S.; Xue, H. (2008). An inositol polyphosphate 5phosphatase functions in phototropin 1 signaling in arabidopis by altering cytosolic Ca2+. Plant Cell, 20, 353-366

Cho, J., Choi, K., Darden, T., Reynolds, P.R., Petitte, J.N., Shears, S.B., (2006). Avian multiple inositol polyphosphate phosphatase is an active phytase that can be engineered to help ameliorate the 
planet's "phosphate crisis". Journal of Biotechnology, 126(2):248-259.

Cowieson, A.J., Acamovic, T., Bedford, M.R., (2004). The effects of phytase and phytic acid on the loss of endogenous amino acids and minerals from broilerchickens. Br. Poult. Sci. 45, 101-108.

Cowieson, A.J., Aureli, R., Guggenbuhl, P., Fru-Nji, F., (2014). Possible involvement of myo-inositol in the physiological response of broilers to high doses of microbial phytase. Anim. Prod. Sci. 55, 710-719.

Cromwell, G. L. and Coffey, R. D. (1991). Phosphorus: a key essential nutrient, yet a possible major pollutant. Its central role in animal nutrition. - In: Lyons, T. P. (ed.), Biotechnology in the feed industry. Alltech Tech Publishers, Nicholasville, KY, pp. 133 - 145.

Doria E, Galleschi L, Calucci L, Pinzino C, Pilu R, Cassani E, Nielsen E (2009). Phytic acid prevents oxidative stress in seeds: evidence from a maize (Zea mays L.) low phytic acid mutant. J. Exp. Bot. 60: 967-978.

Dungelhoef, M., Rodehutscord, M., Spiekers, H., Pfeffer, E., (1994). Effects of supplemental microbial phytase on availability of phosphorus contained in maize, wheat and triticale to pigs. Animal Feed Science and Technology, 49(1-2):1-10.

Eeckhout, W., De Paepe, M., (1994). Total phosphorus, phytate-phosphorus and phytase activity in plant feedstuffs. Anim. Feed Sci. Technol. 47, 19-29.

Efanov, A.M., Zaitsev, S.V., Berggren, P.O., (1997). Inositol hexakisphosphate stimulates non-Ca2+-mediated and primes $\mathrm{Ca} 2+-$-mediated exocytosis of insulin by activation of protein kinase C. Proceedings of the National Academy of Sciences of the United States of America, 94(9): 4435-4439.
Egli, I., Davidsson, L., Juillerat, M.A., Barclay, D., Hurrell, R.F., (2002). The influence of soaking and germination on the phytase activity and phytic acid content of grains and seeds potentially useful for complementary feeding. Journal of Food Science, 67(9):34843488.

Ertl, D. S., Young, K. A. and Raboy, V. (1998). Plant genetic approaches to phosphorus management in agricultural production. - J. Environ. Qual. 27: 299 $-304$.

Filikov, A.V., James, T.L., (1998). Structurebased design of ligands for protein basic domains: Application to the HIV-1 Tat protein. Journal of Computer-Aided Molecular Design, 12(3):229-240.

Gao, C. Q. et al., (2012). Evaluation of the compositional and nutritional values of phytase transgenic corn to conventional corn in roosters. Poult Sci. 91, 11421148 ,

Gong, C. Y. \& Wang, T. (2013). Proteomic evaluation of genetically modified crops: current status and challenges. Front Plant Sci. 4, 41, doi:10.3389/fpls.2013.00041 (2013).

Grases, F., Costa-Bauza, A., Perello, J., Isern, B., Vucenik, I., Valiente, M., Munoz, J.A., Prieto, R.M., (2006). Influence of concomitant food intake on the excretion of orally administered myoinositol hexaphosphate in humans. Journal of Medicinal Food, 9(1):72-76.

Greiner, R., Carlsson, N.G., (2006). MyoInositol phosphate isomers generated by the action of a phytate-degrading enzyme from Klebsiella terrigena on phytate. Canadian Journal of Microbiology, 52(8):759-768.

Haros, M.; Rosell, C.M.; Benedito, C. (2001). Fungal phytase as a potential breadmaking additive. Eur. Food Res. Technol., 213, 317-322. 
Hawkins, P.T., Poyner, D.R., Jackson, T.R., Letcher, A.J., Lander, D.A. and Irvine, R.F. (1993) Inhibition of iron-catalysed hydroxyl radical formation by inositol polyphosphates: a possible physiological function for myo-inositol hexakisphosphate. Biochem. J. 294, 929-934.

IUB, 1979. Pp. 242-247 in: Enzyme Nomenclature: Recommendations of the Nomenclature Committee of the International Union of Biochemistry. Academic Press, New York, NY.

Jog, S.P., Garchow, B.G., Mehta, B.D., Murthy, P.P.N., (2005). Alkaline phytase from lily pollen: Investigation of biochemical properties. Archives of Biochemistry and Biophysics, 440(2):133-140.

[doi:10.1016/j.abb.2005.05.029]

Josefsen, L.; Bohn, L.; Sorensen, M.; Rasmussen, S. (2007). Characterization of a multifunctional inositol phosphate kinase from rice and barley belonging to the ATP-grasp superfamily. Gene, 397,114-125.

Kornegay, E.T., (1999). Application of phytase for retention of nonphosphorus nutrients. Proc. MD Nutr. Conf. 46:83103.

Kuiper, H. A., Kleter, G. A., Noteborn, H. P. J. M., and Kok, E. J. (2001).Assessment of the food safety issues related to genetically modified foods. Plant J. 27, 503-528.

Ladics, G. S., Bartholomaeus, A., Bregitzer, P., Doerrer, N. G., Gray, A., Holzhauser, T., et al., (2015). Genetic basis and detection of unintended effects in genetically modified crop plants. Transgenic Res. 24,587-603.

Larson, S.R., Rutger, J.N., Young, K.A. and Raboy, V. (2000) Isolation and genetic mapping of a non-lethal rice (Oryza sativa L.) low phytic acid 1 mutation. Crop Sci. 40, 1397-1405
Lee, S.H., Park, H.J., Chun, H.K., Cho, S.Y., Cho, S.M., Lillehoj, H.S., (2006). Dietary phytic acid lowers the blood glucose level in diabetic KK mice. Nutrition Research, 26(9):474-479.

Lei, X. G., and Porres, J. M. (2003) Phytase enzymology, applications, and biotechnology. Biotechnol. Lett. 25, 1787-1794.

Lei, X.G.; Weaver, J.D.; Mullaney, E.; Ullah, A.H.; Azain, M.J. (2013). Phytase, a new life for an -oldll enzyme. Аnnu. Rev. Anim. Biosci. 2013, 1, 283-309.

Lemtiri-Chlieh, F., MacRobbie, E.A.C., Webb, A.A.R., Manison, N.F., Brownlee, C., Skepper, J.N., Chen, J., Prestwich, G.D. and Brearley, C.A. (2003) Inositol hexakisphosphate mobilizes an endomembrane store of calcium in guard cells. Proc. Natl Acad. Sci. USA, 100, 10091-10095.

Liu K, Peterson KL, Raboy V (2007). Comparison of the phosphorus and mineral concentrations in bran and abraded kernel fractions of normal barley (Hordeum vulgare) cultivar versus four low phytic acid isolines. $J$. Agric. Food. Chem. 55: 4453-4460.

Liu, Z.; Cheng, F.; Zhang, G. (2005). Grain phytic acid content in japonica rice as affected by cultivar and environment and its relation to protein content. Food Chemistry, v. 89, n. 1, p.49-52

Lott, J.N.A., Ockenden, I., Raboy, V., Batten, G.D., (2000). Phytic acid in crop seeds and fruits: a global estimate. Seed Sci. Res. 10, 11-33.

M.J. Berridge, R.F. Irvine (1989), Inositol phosphates and cell signaling, Nature 341: 388-389

Macbeth, M.R., Schubert, H.L., van Demark, A.P., Lingam, A.T., Hill, C.P., Bass, B.L., (2005). Inositol hexakisphosphate is bound in the ADAR2 core and required for RNA editing. Science, 309 (5740):1534-1539. 
Mendoza, C., Viteri, F. E., Lonnerdal, B. et al., (1998). Effect of genetically modifi ed, low-phytic acid maize on absorption of iron from tortillas. - Am. J. Clin. Nutr. 68: 1123 - 1128.

Murphy, A.; Otto, B.; Brearley, C.; Carr, J.; Hanke, D. (2008). A role for inositol hexakisphosphate in the maintenance of basal resistance to plant pathogens. Plant J. 2008, 56, 638-652

Nahm, K.H., (2002). Efficient feed nutrient utilization to reduce pollutants in poultry and swine manure. Critical Reviews in Environmental Science and Technology, 32(1):1-16. [doi:10.1080/10643380290813435]

Neevel, J.G., (1995). Phytate-A potential conservation agent for the treatment of ink corrosion caused by irongall inks. Restaurator-International Journal for the Preservation of Library and Archival Material, 16(3):143-160.

Neevel, J.G., (1995). Phytate-A potential conservation agent for the treatment of ink corrosion caused by irongall inks. Restaurator-International Journal for the Preservation of Library and Archival Material, 16(3):143-160.

Nelson, T.S., (1968). Effect of phytate on the calcium requirement of chicks. Poult. Sci. 47, 1985-1989.

O'Dell BL, Boland AR, Koirtyohann SR (1972) Distribution of phytate and nutritionally important elements among the morphological components of cereal grains. J Agric Food Chem 20:18-724

Ockenden, I., Dorsch, J.A., Reid, M.M., Lin, L., Grant, L.K., Raboy, V., Lott, J.N.A., (2004). Characterization of the storage of phosphorus, inositol phosphate and cations in grain tissues of four barley (Hordeum vulgare L.) low phytic acid genotypes. Plant Science, 167(5):11311142.

Oh, B.C., Kim, M.H., Yun, B.S., Choi, W.C., Park, S.C., Bae, S.C., Oh, T.K., (2006).
$\mathrm{Ca} 2+$-inositol phosphate chelation mediates the substrate specificity of beta-propeller phytase. Biochemistry, 45(31):9531-9539.

Onomi, S., Okazaki, Y., Katayama, T., (2004). Effect of dietary level of phytic acid on hepatic and serum lipid status in rats fed a high-sucrose diet. Bioscience Biotechnology and Biochemistry, 68(6):1379-1381.

Persson, H., Turk, M., Nyman, M., Sandberg, A.S., (1998). Binding of $\mathrm{Cu} 2+, \mathrm{Zn} 2+$ and $\mathrm{Cd} 2+$ to inositol tri-, tetra-, penta, and hexaphosphates. Journal of Agricultural and Food Chemistry, 46(8):3194-3200.

Pilu, R.; Panzeri, D.; Gavazzi, G.; Rasmussen, S.; Consonni, G.; Nielsen, E. (2003). Phenotypic, genetic and molecular characterization of a maize low phytic acid mutant (lpa241). Theor. Appl. Genet., 107, 980-987.

Poiana MA, Alexa E, Bragea M (2009) Studies concerning the phosphorus bioavailability improvement of some cereals used in nourishment. Roumanian Biotechnol Lett 14:44674473

Raboy, V. (2002). Progress in breeding low phytate crops. Am. Soc. Nutr. Sci. 2002, 132 (3), 503S-505S.

Raboy, V., Gerbasi, P. F., Young, K. A. et al., (2000). Origin and seed phenotype of maize low phytic acid 1-1 and low phytic acid 2-1. - Plant Physiol. 124: $355-368$.

Raboy, V., Young, K. A., Dorsch, J. A. et al., (2001). Genetics and breeding of seed phosphorus and phytic acid. - J. Plant Physiol. 158: 489 - 497.

Reale, A., U. Konietzny, R. Coppola, E. Sorrentino and R. Greiner, (2007). The importance of lactic acid bacteria for phytate degradation during cereal dough fermentation. J. Agric. Food Chem., 55: 2993-2997. 
Reddy, N.R. (2002). Occurrence, Distribution, Content, and Dietary Intake of Phytate. In Food Phytates; Reddy, N.R., Sathe, S.K., Eds.; CRC Press: Boca Raton, FL, USA, 2002.

Saiardi, A.; Caffrey, J.; Snyder, S.; Shears, S. (2000). Inositol polyphosphate multikinase (ArgRIII) determines nuclear mRNA export in Saccharomyces cerevisiae. FEBS Lett. 2000, 468, 28-32.

Sala, M., Kolar, J., Strlic, M., Kocevar, M., (2006). Synthesis of myo-inositol 1,2,3tris- and 1,2,3,5-tetrakis(dihydrogen phosphate)s as a tool for the inhibition of iron-gall-ink corrosion. Carbohydrate Research, 341(7):897902.

Sandberg, A.S., Brune, M., Carlsson, N.G., Hallberg, L., Skoglund, E., RossanderHulthen, L., (1999). Inositol phosphates with different numbers of phosphate groups influence iron absorption in humans. American Journal of Clinical Nutrition, 70(2):240-246.

Selvam, R., (2002). Calcium oxalate stone disease: Role of lipid peroxidation and antioxidants. Urol. Res., 30(1):35-47.

Shears, S.(2001). Assessing the omnipotence of inositol hexakisphosphate. Cell. Signal., 13, 151-158.

Shi J, Wang H, Schellin K, Li B, Faller M, Stoop JM, Meeley RB, Ertl DS, Ranch JP, Glassman K (2007). Embryospecific silencing of a transporter reduces phytic acid content of maize and soybean seeds. Nat Biotechnol 25:930-937

Shi, J., Wang, H. and Hazebroek, J. (2005). The maizelowphyticacid 3 encodes a myo-inositol kinase that plays a role in phytic acid biosynthesis in developing seeds. - Plant J. 42: $708-719$.

Skoglund, E., T. Larsen and A. S. Sandberg, (1997). Comparison between steeping and pelleting a mixed diet at different calcium levels on phytate degradation in pigs. Can. J. Anim. Sci. 77:471-477.

Spencer, J. D., Allee, G. L. \& Sauber, T. E. (2000a). Phosphorus bioavailability and digestibility of normal and genetically modified low-phytate corn for pigs. J. Anim. Sci. 786: 675-681.

Spencer, J.D., G.L. Allee and T.E. Sauber. (2000b). Grow-finish performance and carcass characteristics of high lean growth barrows fed normal and genetically modified low phytate corn. J. Anim. Sci. 78:1529-1536.

Storcksdieck, S., Bonsmann, G., Hurrell, R.F., (2007). Iron-binding properties, amino acid composition, and structure of muscle tissue peptides from in vitro digestion of different meat sources. Journal of Food Science, 72(1): S019S029.

Tan Y, Yi X, Wang L, Peng C, Sun Y, Wang D, Zhang J, Guo A and Wang X (2016) Comparative Proteomics of Leaves from Phytase-Transgenic Maize and Its Non-transgenic Isogenic Variety. Front. Plant Sci. 7:1211.

Tuntawiroon, M., Sritongkul, N., Brune, M., Rossanderhulten, L., Pleehachinda, R., Suwanik, R., Hallberg, L., (1991). Dose-dependent inhibitory effect of phenolic-compounds in foods on nonheme-iron absorption in men. American Journal of Clinical Nutrition, 53(2):554-557.

Ullah AHJ, Phillippy BQ (1988) Immobilization of Aspergillus ficuum phytase: product characterization of the bioreactor. Prep Biochem 18: 483489

Vasca, E., Materazzi, S., Caruso, T., Milano, O., Fontanella, C., Manfredi, C., (2002). Complex formation between phytic acid and divalent metal ions: A solution equilibria and solid state investigation. Analytical and Bioanalytical Chemistry, 374(1):173-178. 
Vats, P., Bhattacharyya, M.S., Banerjee, U.C., (2005). Use of phytases (myo-inositol hexakisphosphate phosphohydrolases) for combatting environmental pollution: A biological approach. Critical Reviews in Environmental Science and Technology, 35(5):469-486.

Vidal, N., Barbosa, H., Jacob, S. \& Arruda, M. (2015). Comparative study of transgenic and non-transgenic maize (Zea mays) flours commercialized in Brazil, focussing on proteomic analyses. Food Chem. 180, 288-294.

Vohra, P., Gray, G.A., Kratzer, F.H., (1965). Phytic acid-metal complexes. Proceedings of the Society for Experimental Biology and Medicine, 120(2):447-449.

Vucenik, I., Shamsuddin, A.M., (2006). Protection against cancer by dietary IP6 and inositol. Nutrition and Cancer, 55(2):109-125.

Wang, Y., Gao, X.R., Su, Q., Wu, W., An, L.J., (2007). Expression of a heat stable phytase from Aspergillus fumigates in tobacco (Nicotiana tabacum L. cv. NC89). Indian Journal of Biochemistry and Biophysics, 44(1):26-30.

Ward, K.A., (2001). Phosphorus-friendly transgenics. Nature Biotechnology, 19(5):415-416.
Wodzinski RJ, Ullah, AH. (1996) Phytase.Adv Appl Microbiol 42:263301

York, J.D., (2006). Regulation of nuclear processes by inositol polyphosphates. Biochimica et Biophysica Acta (BBA)Molecular and Cell Biology of Lipids, 1761(5-6):552-559. [doi:10.1016/j. bbalip.2006.04.014]

Zhang, Y., Liu, C., Li, Y. \& Wu, K. (2010). Phytase transgenic maize does not affect the development and nutrition utilization of Ostrinia furnacalis and Helicoverpa armigera. Environ Entomol. 39, 1051-1057.

Zhou, J. R. and Erdman, J. W. Jr. (1995). Phytic acid in health and disease. - Crit. Rev. Food Sci. Nutr. 35: 495 - 508.

Zolla, L., Rinalducci, S., Antonioli, P. \& Righetti, P. G. (2008). Proteomics as a complementary tool for identifying unintended side effects occurring in transgenic maize seeds as a result of genetic modifications. J Proteome Res. 7, 1850-1861

Zyla, K., Dulinski, R., Pierzchalska, M., Grabacka, M., Jozefiak, D. Swiatkiewicz, S., (2013). Phytases and myo-inositol modulate performance, bone mineralization and alter lipid fractions in the serum of broilers. $J$. Anim. Feed Sci. 22, 56-62.

\section{How to cite this article:}

Vimla Singh, Rakesh Mehra, Sunaina Bisht, Meena Shekhar, and Arvind Kumar. 2018. Phytin: A Nutritional Inhibitor in Food and Feed - Review of Strategies and Challenges to Overcome the Menace in Maize. Int.J.Curr.Microbiol.App.Sci. 7(06): 3264-3279. doi: https://doi.org/10.20546/ijcmas.2018.706.384 